\title{
OS CONHECIMENTOS DAS ÁREAS VERSUS O OBJETO DAS ÁREAS: o currículo ressignificado
}

\author{
THE KNOWLEDGE OF THE AREAS VERSUS THE OBJECT OF THE AREAS: the ressignified curriculum
}

Adreana Dulcina Platt ${ }^{1}$ Marcelo Silveira ${ }^{2}$

Resumo: Este estudo investiga uma proposta de reorientação curricular para a educação escolarizada. Consideramos como ponto de partida a ressignificação dos saberes oficialmente para os currículos escolares no Brasil. A intenção inicial será destacar a problematização de que exista, nas diferentes áreas do conhecimento, um específico objeto de estudo necessário a incorporação pelos indivíduos para que lidem com a complexidade social. A tese aponta que, ao determinar o específico de estudo de cada área do conhecimento, é possível ressignificar as relações curriculares pelo realinhamento das perspectivas político-pedagógicas desses saberes, ou seja, compreenderemos as necessidades de formação humana desde o eixo da práxis social, organizado desde o plano da vida cotidiana à incorporação dos saberes científicos mais elaborados.

Palavras-Chave: Educação. Currículo. Reorientação Curricular.

\begin{abstract}
This study investigates a proposal of curricular reorientation for school education. We consider as a starting point the re-signification of the knowledge officially for the school curricula in Brazil. The initial intention will be to highlight the problematization that there is, in the different areas of knowledge, a specific object of study necessary for incorporation by individuals to deal with social complexity. The thesis points out that, in determining the specific study of each area of knowledge, it is possible to re-significate the curricular relations by realigning the political-pedagogical perspectives of these knowledge, that is, we will understand the needs of human formation from the axis of social praxis, organized from the plane of daily life to the incorporation of the most elaborate scientific knowledge.
\end{abstract}

Keywords: Education. Curriculum. Curricular. Reorientation.

\section{INTRODUÇÃO - "O CURRÍCULO”}

Sempre será possível elencar diferentes concepções teóricas que se atentam na definição de “currículo" (Tyler, 1974; Moreira; Silva, 1994; Gimeno Sacristán, 1998, 2002; Moreira, 1999, entre outros).

Este corpo conceitual, entretanto, em significativo volume, parte da sistemática escolar para compreender o arcabouço legítimo da organização curricular com vistas a responder satisfatoriamente às questões que emergem, mais detidamente, em referência aos conhecimentos relevantes aos sujeitos, recortados do acúmulo histórico humano assim como na apropriação dos códigos e representatividades de seu tempo. Neste estudo, contudo, nos deteremos - anteriormente ao conceito das áreas do conhecimento escolar e do mapa curricular que legitimamente se desenvolve nos institutos educacionais hodiernos - em dissertar uma concepção de anterioridade ao logismo de "currículo".

Compreendemos que a dimensão pública escolar, respondendo pela maioria do acesso da

\footnotetext{
${ }^{1}$ Doutora em Educação pela Universidade Estadual de Campinas. Professora associada da Universidade Estadual de Londrina. E-mail: adplatt@uel.br. ORCID: http://orcid.org/0000-0002-2188-1260.

2 Doutor em Letras pela Universidade Estadual de Londrina. Professor adjunto da Universidade Estadual de Londrina. E-mail: celosilveira@gmail.com. ORCID: http://orcid.org/0000-0002-3903-6292.
} 
população, foi por um lado (e continua sendo) resultado de uma exaustiva e contínua luta entre classes de interesses antagônicos e, de outro, uma grande alavanca para as relações de produção que se encetam na estruturação da modernidade (Frigotto, 1984). Porém, convém desvelarmos que nestes quase trezentos anos de história institucional da educação pública - para as grandes massas populares -, os dados e as reconhecidas crises paradigmáticas que percorrem os espaços escolares, as políticas a eles voltadas, as teses da racionalidade didático-pedagógica que povoam uma concepção de trato às diferentes culturas e às perspectivas cognitivas e sociais não têm se atentado devidamente, no nosso entender, a um "elemento de anterioridade" ao processo de escolarização: o currículo que compreende o desenvolvimento humano pleno e que ocorre independentemente e ao largo da sistematização escolar, mas que se dá via ato educacional (Garcia, 1977).

\section{CONCEITO DE “EDUCAÇÃO PARA A FORMAÇÃO PLENA" - OU EDUCAÇÃO OMNILATERAL}

Quando se pensa na educação em termos de formação humana, não é possível reduzi-la apenas à posse de uma série de competências (SANTOS, 2002, p. 142).

O conceito de "formação humana plena" tem por fundamentação a própria história da humanidade, uma vez que suscita um necessário retorno às bases do processo conceitualmente denominado de hominização-humanização (Duarte, 1999).

Conforme Duarte (1999) e Saviani (2011), esse processo se dá a partir do momento em que os indivíduos da espécie humana especializam determinados elementos que serão centrais ao seu desenvolvimento, mas que, a princípio e tais quais os demais animais, cercavam três necessidades essenciais: a alimentação, a reprodução, a proteção (Malinowski, 1975; Reis, 2003). Essas atividades elementares serão propulsoras de ações com vistas a uma resposta imediata quanto ao problema que emergia (centralmente cercado às suas necessidades "básicas" - atividade imediata à fonte causal). A especialização advinda dessa base instintiva permitiu que os indivíduos da espécie humana não mais se fixassem na condição de seres coletores, submetidos à natureza, para assim modificá-la, ampliando sua inserção nela, e, consequentemente, suas necessidades existenciais, enquanto resultado das novas demandas.

Quais seriam os elementos essenciais à apropriação dos indivíduos da espécie humana que os destacariam dos demais animais vivos? Serão os aspectos que com o exercício da atividade objetiva, material (trabalho) transformam a natureza circundante, o próprio indivíduo e os demais seres humanos. Isso se dá, uma vez que, no desenvolvimento da atividade objetiva, desencadeia-se um "processo" de transformação dos aspectos objetivos e subjetivos.

As premissas que elencamos enquanto feixes essenciais e especiais desse desenvolvimento pleno (omnilateral) da condição de "espécie humana" para a condição de "ser humano" podem ser sistematizados no esquema, a seguir: 
Gráfico 1: Acúmulo histórico x Produção humana no tempo e no espaço

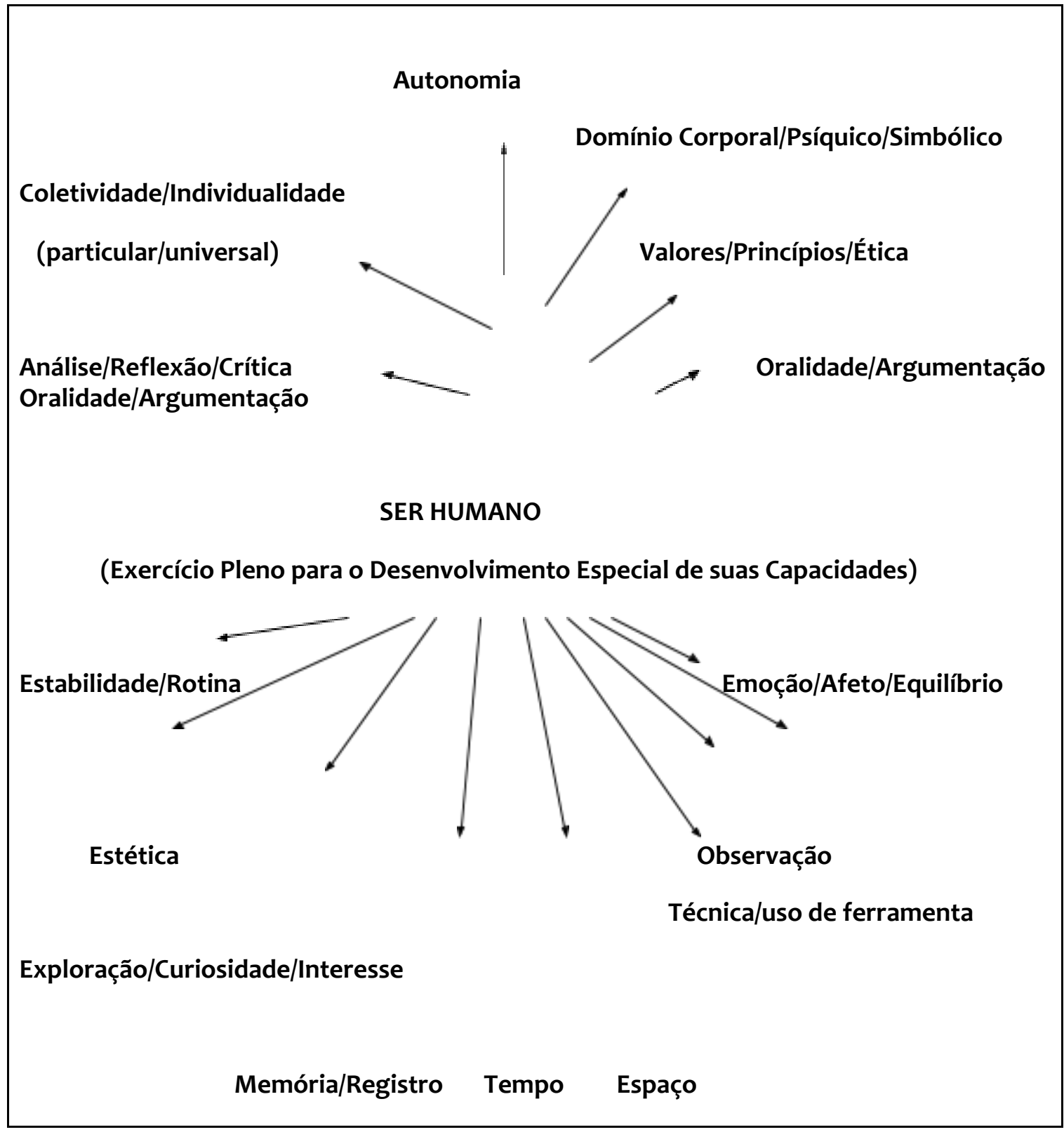

Fonte: Baseado em Marx (1982) e Duarte (2001)3.

Com esse esquema, procuramos contemplar os elementos que sustentam a verdadeira máxima curricular: o volume de saberes que organizam os indivíduos diante da atividade objetiva material e de sua produção imaterial, seu plano de formação que se desencadeia a partir das relações que estabelece em meio ao exercício da atividade material e que transforma o outro e a si mesmo.

Toda a história da humanidade parte da totalidade desse currículo - de um currículo que permite que a humanidade não principie do "zero" (Kosik, 1995). O autor não trata do currículo enquanto elenco de saberes escolares, mas enquanto conceito ampliado de "currículo de formação humana", discorrendo sobre o acúmulo de saberes da práxis socialmente aceita e veiculada, para destacar que é

3 Segundo Marx (apud MARX; ENGELS, 1982, p. 155), para a atividade da práxis histórica transformadora da natureza, será necessária a existência de indivíduos humanos vivos e organizados fisicamente para agirem por meio do trabalho na satisfação de suas necessidades. Este quadro apresenta os elementos relevantes e atualizados requeridos ao indivíduos para agirem diante da complexidade social existente. 
assunto irreversível na formação dos sujeitos e o caminho para compreender a história de nossa forma tão complexa de vida. Esse currículo significará os saberes determinantes ao pleno desenvolvimento da humanidade porquanto sua especialização o destaca dos demais animais que continuam submetidos à natureza.

\section{UMA PROPOSTA DE REORIENTAÇÃO CURRICULAR}

Toda a construção histórica é necessariamente seletiva (DEWEY apud SCHAFF, 1978, p. 118).

Ao selecionarmos os elementos que determinam a passagem de nossa condição primitiva de espécie animal (hominização) - sustentados unicamente em nossos instintos - para a ampliação de nosso desenvolvimento enquanto seres humanos (humanização), estamos entendendo que esses saberes serão "conditio sine qua non" para a atividade de formação das gerações que nos precedem.

Essa organização formativa a partir da operacionalização daquilo que Saviani (2011) descreve como o exercício da humanidade no homem se traduz em todo ato educativo. Este será seu objeto de aplicabilidade. O ser humano, ao longo do processo de seu desenvolvimento, acumula a história de sua atividade objetiva material, destacando em determinado momento os saberes e conhecimentos relevantes enquanto resposta às suas necessidades (Platt, 2006, 2009).

Compomos um esquema para melhor explicar este dado:

Gráfico 2: Acúmulo histórico x Produção humana no tempo e no espaço
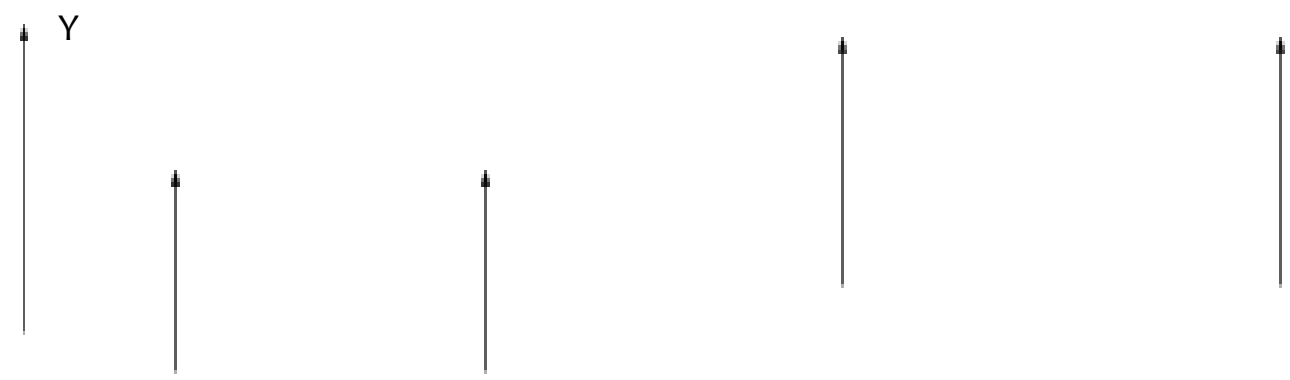

\footnotetext{
X Ano 12

Ano 275

Ano1308

Ano

2018

$\mathrm{Y}=$ Bloco da produção humana especialização no tempo e no espaço determinado (ano aleatório).

$X=$ Acúmulo histórico (tempo). Dá-se partida à contagem desde a presença do homo sapiens, que se dá antes de Cristo.
}

Fonte: o autor.

O traço horizontal determina o volume do conhecimento acumulado na história da humanidade a partir de ruptura hominização-humanização. Aqui se destaca o traço do acúmulo do trabalho humano enquanto produto coletivo. No traço vertical temos materializado (em datas escolhidas aleatoriamente) o elemento do conhecimento histórico que será relevante para um especial momento da humanidade serão os saberes aplicados e determinantes para as condições de existência dos seres humanos em seu tempo e que são aplicados objetivamente em destaque de sua produção, intercâmbio e sinalizam os códigos de seu tempo em relação ao seu desenvolvimento (aqui se destaca a singularidade dos 
agrupamentos humanos).

A cada período histórico são pontuais os grupos que hegemonicamente detêm os processos de produção e o seu intercâmbio ${ }^{4}$. Tais grupos marcam-se ao longo da história da humanidade e um dos atributos para a manutenção de tal poder será a "alienação" dos aspectos imateriais e dos códigos que compõem o arcabouço de seu poder. Ou seja, é pertinente considerar que as classes que exercem domínio num determinado momento histórico da humanidade buscam a manutenção de seu poder. Para tal, os pressupostos desse domínio ocorrem tanto no âmbito material quanto imaterial (assim como ocorre em todo o produto humano), assim faz-se necessária não somente a conquista das forças infraestruturais e de produção, mas também dos aparatos supraestruturais por onde se sustentam os princípios e as fronteiras para a ação cotidiana das camadas dominadas.

A educação escolarizada enquanto instituto cujos eixos de formalização são eminentemente atrelados ao Estado será uma das forças supraestruturais que colabora na sustentação da hegemonia dominante (assim como também será uma força de contra-hegemonia/resistência a esta). Seus elementos interiores - parâmetros curriculares, gestão e administração, fundos oriundos de programas federais, a capacitação voltada aos seus profissionais, o calendário escolar, os espaços escolares, etc. são "encharcados" desse discurso dominante. Sobre esta questão, Santos (2002, p. 141) afirma:

Tem sido muito discutido como a configuração de novos mapas econômicos, sociais, políticos e culturais coloca novas exigências para a instituição escolar. Está em curso, hoje, uma profunda reestruturação produtiva e uma abrangente reorganização da sociedade, ancoradas no uso intensivo e em larga escala da microeletrônica e eletrônica digital. Essas transformações [...] mudam as concepções acerca do perfil do trabalhador, tendo, consequentemente, um grande impacto na maneira de se pensar a educação escolar. Em decorrência disso, assiste-se a uma intensificação das reformas curriculares, voltadas para o desenvolvimento no aluno de habilidades tais como: criatividade, autonomia, desenvolvimento do pensamento divergente e capacidade de comunicação.

Se olharmos novamente para o esquema que elaboramos quanto aos elementos que enunciam o acúmulo da história da humanidade (horizontal) assim como dos elementos relevantes em determinado momento histórico (vertical), veremos que, de todo o volume de saberes produzidos e reconstruídos, serão elencados os saberes relevantes segundo os ditames da estruturação produtiva, dos valores correspondentes a esse sistema e seus discursos, do conhecimento técnico-instrumental, etc., "requisitados" e validados à veiculação social. A escola, portanto, será um instituto essencial a qualquer projeto hegemônico. Sua função social é confundida com a própria racionalidade civilizatória. Segundo Frigotto (1984, p. 16),

Quanto ao primeiro sentido - teoria do desenvolvimento - concebe a educação como produtora de capacidade de trabalho, potenciadora de trabalho e, por extensão, potenciadora da renda, um capital (social e individual), um fator do desenvolvimento econômico e social. Quanto ao segundo sentido - teoria da educação - a ação pedagógica, a prática educativa escolar, reduz-se a uma questão técnica, a uma tecnologia educacional cuja função precípua é ajustar requisitos educacionais a pré-requisitos de uma ocupação de mercado de trabalho de uma dada sociedade.

Esse objetivo está articulado estreitamente com os elementos dirigidos aos saberes

$4 \quad$ Esclarecemos esse dado apreendendo que esse movimento ocorre concomitantemente com os elementos de contra-hegemonia, de oposição e contradição aos determinantes, uma vez que essas forças compõem o espaço social em contínuo conflito. 
prático-operatórios (instrumentais) que os grupos hegemônicos pretendem aplicar sobre os saberes que validam e mantêm seu projeto de poder, por meio da dinâmica acima descrita. Ou seja, existem os elementos centrais do currículo de formação humana praticados atualmente, que dialogam necessariamente com as práticas das classes dominantes, reificadas no corpo social ampliado.

Nossa tese, porém, destaca que se a humanidade investe na formação humana com ênfase na cultura e dos condicionantes técnico-funcionais conforme as necessidades produtivas num determinado período histórico (em nosso caso com a cultura do capital), "perde" de vista os produtos acumulados e registrados ao longo da atividade humana desde a ruptura de sua condição de submissão aos ditames da natureza para, assim, transformá-la por meio do trabalho (objetiva e subjetivamente). Tememos, portanto, a impossibilidade da educação dos sujeitos com vistas ao seu pleno desenvolvimento. Sobre essa questão lanni (1999, p. 73) asserta que

A cultura do capitalismo seculariza tudo o que encontra pela frente e pode transformar muita coisa em mercadoria, inclusive signos, símbolos, emblemas, fetiches. Tudo se seculariza, instrumentaliza, desencanta. Esta é uma exigência da racionalização formal, pragmática, definidos em termos de fins e meios objetivos imediatos. Uma racionalização cada vez mais vazia de valores gerais e particulares que não podem traduzir-se nos termos do status quo. Ao refletir sobre a progressiva universalização dessa racionalidade Weber 'demonstra a nítida resistência da moderna racionalidade formal da ordem social e econômica diante de valores de igualdade, fraternidade e caridade, e mostra como a racionalidade formal impulsiona os interesses de grupos economicamente privilegiados'.

O desenvolvimento que aqui recortamos enquanto situação ideal de formação humana será aquele que projeta o investimento educacional a partir da perspectiva omnilateral/omnidimensional ${ }^{5}$ (omni: todo, lateral: lado; dimensional: dimensão). Entendemos que o desenvolvimento amplia-se tanto numa condição quantitativa (volume) quanto qualitativa (diferenciação).

A partir desse aporte é que propomos uma "reorientação do currículo". Sua ressignificação se fundamenta nos princípios de uma educação omnilateral/omnidimensional com vistas ao pleno desenvolvimento humano (Platt, 2006, 2009). Sustentamos essa necessidade, uma vez que partimos do pressuposto de que uma formação situada apenas aos conhecimentos relevantes e singulares de um determinado período fragiliza os indivíduos a cada reestruturação produtiva, por exemplo, onde são requisitados novos aportes técnico-funcionais e socioculturais. Assim, os indivíduos são relegados a uma formação situada apenas ao seu tempo, sujeita ao volume de bens conjunturais de uma sociedade local e ditames internacionais.

\section{UM ESTUDO (DE CASO) SOBRE A EDUCAÇÃO VOLTADA À FORMAÇÃO DE SEU TEMPO: uma análise histórico-crítica ao modelo em Londrina/PR e Florianópolis/SC}

Nosso estudo parte de uma reflexão da realidade e para tanto escolhemos a análise do objeto junto aos municípios de Florianópolis e Londrina. A opção se dá pelo exercício no campo do magistério em ambos os sistemas de ensino. Em Florianópolis, a investigação ao objeto de estudo de cada área do ensino ocorria enquanto projeto de formação aos funcionários (servidores e docentes) em uma determinada unidade de ensino, embora, é preciso registrar, a discussão quanto à necessidade de uma ressignificação curricular tenha sido o projeto de gestão do governo municipal para o período de 93-96, o qual a Secretaria de Municipal de Educação encampou procurando refazer uma leitura do estudo das áreas do conhecimento.

Nossa intenção, entretanto, não será historicizar todo esse período, o que já foi

5 Omnilateralidade segundo Graciani (1994, p. 79) será a intervenção proposital, portanto, político-pedagógica, e que "abrange todos os campos essenciais da realidade humana e natural e todas as dimensões existenciais do ser humano". 
significativamente realizado ${ }^{6}$, mas, sim, sistematizar o movimento em sentido a objetivar a prática pedagógica, a função social de escola, a visão de ser humano e de educação, ou seja, ressignificar a educação plena, omnilateral.

Em Londrina, o espaço foi escolhido também pelo envolvimento com o magistério local, porém, agora com status acadêmico, já que nosso investimento se dá pelo projeto científico ${ }^{7}$ que desenvolvemos junto a uma Universidade situada no interior do Paraná.

O projeto visa investigar o objeto de estudo das áreas do conhecimento que são recortadas pelo currículo escolar, oficial. Dando continuidade aos estudos anteriormente desenvolvidos, conduzimos o destaque da pesquisa às matérias do ensino fundamental mais detidamente.

As áreas selecionadas ao estudo de seu objeto assim o foram porquanto procuramos envolver um único eixo de comparação em ambas as realidades perscrutadas. Foi observado, igualmente, o tempo disponível à intervenção junto ao corpo docente das instituições, o que delimitava o período destinado à investigação da tese por nós proposta.

Portanto, entendendo o tempo e o espaço recortado dos saberes significativos à formação humana através do acúmulo da humanidade e por meio dos conhecimentos recortados para a ação e crítica de seu tempo - códigos da atualidade -, queremos destacar o objeto de estudo dessas áreas do conhecimento (previamente selecionado) para ressignificar toda a atividade educacional desenvolvida no universo escolar, pontuando que nosso recorte (universo de estudo) se dá pela investigação já realizada junto aos docentes das áreas selecionadas nas unidades de ensino em Florianópolis e Londrina.

\section{PARA UMA RESSIGNIFICAÇAO CURRICULAR: a proposta}

A produção das ideias, representações, da consciência está a princípio diretamente entrelaçada com a atividade material e o intercâmbio material dos homens, linguagem da vida real (MARX; ENGELS, 1982, p. 13).

Nossa preocupação não será a de emitir juízos de valor sobre os saberes em si ou relacionarmos sua pertinência a partir do acúmulo humano de que anteriormente falamos, assim quanto à sua validade na atualidade histórica. A tese que defendemos, no entanto, se debruçará na investigação ao específico das áreas do conhecimento que se destacam no currículo escolar para ressignificar a própria práxis escolar. Isso não será possível sem levarmos em consideração a racionalidade premente, conceitual, de "conhecimento", que, por sua vez, será validada por sua incorporação a um instituto oficial - o currículo escolar.

Tratar sobre o "conhecimento" é envolver-se com os elementos que mapeiam as opiniões, as práticas, as teorias, o imaginário - o material e o imaterial.

$6 \quad$ Enquanto dissertações de mestrado podem ser arroladas as de Barreto (1993), Wiggers (1999), Antonio (2000), Britto (2000) etc.; publicações da época também podem ser citadas como o chamado "caderno azul", que se compõe do relato dos trabalhos sistematizados pelos Grupos de Trabalho (GTs) formados por educadores das diferentes áreas do conhecimento e as consultorias convidadas, juntamente com os docentes dessas áreas disciplinares pertencentes às unidades de ensino. 0 material de que dispomos - e que foi publicizado à rede de ensino - não contempla em sua totalidade (ao nosso entender) o objeto da área de ensino de todas as disciplinas, como nos dispomos a investigar desde os idos de 1998.

$7 \quad 0$ estudo que desenvolvemos em uma Universidade no interior do Paraná intitula-se "O Específico das Áreas do Currículo Escolar para o Pleno Desenvolvimento Humano". A pesquisa teve seu início institucional no ano de 2003 e já possui material acumulado e socializado em diferentes eventos científicos, em periódicos nacionais e internacionais e, enquanto resultado, estudos em iniciação cientifica e pós-graduação. 
O volume dos conhecimentos produzidos pela história da humanidade oportunizada a partir das propriedades humanas especiais (registro e linguagem, por exemplo) é recortado em determinado período histórico segundo os matizes da produção e do intercâmbio ali desenvolvidos (Marx; Engels, 1982). A humanidade não principia sempre do zero, conforme Kosik (1995), portanto acumula as informações e as práticas oriundas do trabalho. Por meio desse princípio, educa-se o outro. É o mundo da práxis:

Temos por pressupostos básicos que o conhecimento só nasce da prática com o mundo, enfrentando os seus desafios e resistências e que o conhecimento só tem seu sentido pleno na sua relação com a realidade (Luckesi et al., 1985, p. 49).

Com a complexificação social, complexifica-se igualmente a forma de produção, a satisfação das necessidades e o intercâmbio da produção. Aludimos, portanto, que tal processo se dá por meio da relativização ao volume dos conhecimentos acumulados pela humanidade em penhor aos saberes requisitados em dado período histórico, que surgem conforme as demandas oriundas da produção e consumo; ou seja, a necessidade ao recorte dos conhecimentos produzidos em relação ao modelo de produção pressupõe a exigência de que somente determinados conhecimentos sejam amplamente difundidos e operacionalmente internalizados. Evidentemente, isso não se destacará unicamente ao plano econômico, mas ocorre concomitantemente aos planos sociopolítico e cultural.

Conforme Vázquez (1977, p. 152-153),

O conhecimento é o conhecimento de um mundo criado pelo homem, isto é, inexiste fora da história, da sociedade e da indústria. É isso exatamente segundo Marx - que o materialismo tradicional ignora [...]. Conhecer é conhecer objetos que se integram na relação entre o homem e o mundo, ou entre o homem e a natureza, relação que se estabelece graças à atividade prática humana.

É oportuno acrescentar que o raciocínio até agora tecido sobre o conceito de conhecimento ocorre por meio de um processo coletivo. Esse dado se atesta porquanto o desenvolvimento da humanidade se faz pela práxis histórica e social. Será "a própria realidade do mundo que mediatizará nossas consciências”, ou seja, “o conhecimento é social” (Luckesi et al., 1985, p. 53).

Semeraro, em confluência às teses gramscinianas, disserta que a produção do conhecimento se dá enquanto elemento que,

[...] mais do que um conjunto de técnicas e operações mentais, é a 'filologia vivente da experiência dos particulares imediatos' ${ }^{8}$ dentro de uma visão global e de uma práxis em que política, história e conhecimento não são pensados separadamente, mas são considerados como lugar de formação de sujeitos críticos e ativos, fatores de autodeterminação e hegemonia (SEMERARO, 2001, p. 96).

Com esses aportes iniciais, precisamos agora entender a especificidade tanto da parte do conhecimento das áreas do saber quanto do objeto de estudo de cada uma destas áreas.

Até aqui destacamos que o conhecimento se dá enquanto síntese acumulada, ou produto, da ação humana e enquanto processo dinâmico pelo qual se confluem diferentes práticas e perspectivas que se contrapõem, se afirmam e se reformulam num continuum, sempre agindo sobre a realidade

$8 \quad$ O autor se refere à filologia como "la ciencia que se ocupa de los textos escritos, a través de los cuales pretende reconstruir, lo más fielmente posible, la cultura que dio lugar a esos textos y que subyace a los mismos. El filólogo se sirve, por tanto, del estudio del lenguaje, la literatura y demás manifestaciones escritas, en tanto en cuanto constituyen la expresión de una comunidad cultural determinada". 
concreta - entendida na perspectiva da totalidade categórica. Dessa forma, reiteramos a dialética existente no conhecimento que se opera tanto na dimensão do acúmulo histórico quanto nas especificidades exigidas num dado momento do desenvolvimento produtivo e de seu intercâmbio. Resumindo: cada período histórico se sustentará pelo acúmulo humano até ali proporcionado pelas relações do desenvolvimento tecnológico e social e especializará em determinados períodos os saberes que dinamizam tal produção e intercâmbio, pontuando até seu ápice e seu "esgotamento" (que não significará seu "fim", mas a sua "superação").

Os saberes elencados em determinado período histórico se inscrevem de maneira tácita e expressa. Tácita, por meio da forma reificada pela qual os indivíduos reproduzem nas relações cotidianas o arrefecimento, ou melhor, a massificação aos códigos que operam as relações de produção, naturalizando esses processos. Expressa, quando há o estabelecimento social dos saberes válidos documentados pelos mecanismos burocráticos institucionais (currículo, por exemplo) que deverão ser apreendidos para a formação das atuais e novas gerações de indivíduos na convivência e manutenção do status quo. Segundo Cardoso (2001, p. 81),

O surgimento da humanidade num campo de discurso corresponde a uma nova maneira de existência social em que as pessoas são ao mesmo tempo transformadas em sujeitos e reificadas como objetos do conhecimento, como 'corpos' situados num campo de forças constituído por estratégias de poder que são também estratégias de conhecimento tendentes a instituir uma integração do sujeito no mesmo campo (grifos no original).

Finalmente, entendemos que as diferentes áreas do conhecimento possuem a tensão tanto entre o seu elemento totalizador, enquanto produto da história humana, quanto ao seu elemento especial, por meio de seu código epistêmico.

A partir do destaque realizado a esses aportes, podemos refletir mais detidamente sobre o objeto de estudo das áreas do conhecimento, com especial atenção aos saberes selecionados nos currículos escolares atuais e, ainda, como poderíamos encontrar neste, os elementos que ressignificariam as práticas curriculares e pedagógicas.

Sem adentrar em "vísceras" epistemológicas que historiciam a caminhada das teorias do conhecimento a partir das diferentes perspectivas grassamente difundidas, temos uma realidade que, de forma proposital, se organiza em saberes e que se detém em difundir conceitos segundo as particularidades dos conhecimentos por elas perscrutados.

Conforme a análise que até aqui elaboramos, tais saberes ser darão em áreas selecionadas para compor a estrutura instrumental do currículo, que se encontra estreitamente articulado ao modelo de produção e às formas de intercâmbio dessa produção. Esse será um importante divisor objetivo para a construção de uma dada realidade e que será amplamente difundido pelos diferentes institutos sociais consolidados em toda a sociedade.

Para uma ressignificação curricular com vistas ao pleno desenvolvimento humano, temos por premissa o destaque de determinados componentes à produção do conhecimento para o pleno desenvolvimento humano:

A) saberes que denunciam o produto da ação humana (objetiva e subjetiva);

B) questões objetivas do ser humano e da sociedade (situadas e reconhecidas no tempo e espaço);

C) concepção omnilateral de desenvolvimento humano. 
Quando falamos em currículo, na verdade estamos nos referindo ao volume de possibilidades formativas que estão disponíveis, material e culturalmente aos indivíduos. A construção desse conceito de currículo nasce da análise de que, independentemente do processo de escolarização (que é uma prática institucional relativamente recente), os indivíduos se formam e se desenvolvem. Caso contrário, a humanidade não teria condições de perpetuar às gerações subsequentes o acúmulo objetivo e subjetivo elaborado a partir de suas práticas sociais. Surge daí, conceitualmente, a concepção de que existe um "currículo" que existe além dos muros da instituição escolar. Podemos apontar, da mesma forma, que tais práticas (as que não são organizadas/sistematizadas) também são encontradas no interior das próprias unidades de ensino. Jurjo Santomé (1998) asserta com propriedade da presença do "currículo oculto" que se desencadeia a partir das práticas que circulam em toda a organização escolar, mas que não se encontram pontualmente/oficialmente construídas. Desse modo, podemos encontrar em simples rotinas um processo pedagógico e formativo (como a "pedagogia do olhar", que pode se dar de forma repreensiva ou estimuladora sobre os comportamentos/atitudes).

A construção do currículo formal nasce a partir desses acúmulos sociais e que, por sua vez, são elaborados dentro de outros determinantes que validam a manutenção dos saberes ou o seu contrário. Isso pode ser mais bem refletido se, pari passu a este estudo, estivermos detalhando a história da ciência e sua contribuição para o desenvolvimento humano.

O currículo escolar ao qual temos acesso hoje possui, dentre suas especificações, a qualidade de ter um núcleo comum para a formação do alunado que frequenta a instituição de ensino, e isso se dá, no caso brasileiro, para qualquer região: são estabelecidos parâmetros mínimos que apenas se diversificam no encaminhamento do procedimento pedagógico e podem variar (depois de garantido o núcleo básico) também em até $25 \%$ com outros saberes considerados relevantes (Moreira, 2003).

É interessante verificar que a discussão curricular tem gravitado em meio a conhecimentos reconhecidos e validados socialmente, assim como as práticas pedagógicas debruçadas no estudo da interlocução do processo ensino-aprendizagem, sem, no entanto, deter-se na discussão aos núcleos de estudo (objeto) desses conhecimentos.

A grande preocupação do processo curricular não se encontra no arcabouço dos conteúdos que advêm das áreas do conhecimento. Entendemos que esse tópico se localiza, em grau de importância, num momento seguinte, pois a grande questão que deve desencadear o planejamento curricular é o conceito de desenvolvimento humano, pois, a partir das diferentes áreas em que esse movimento ocorra, é possível orientar o processo de formação dos indivíduos.

\section{Conforme Tavares (1992 apud PREFEITURA MUNICIPAL DE FLORIANÓPOLIS, 1996),}

[...] o conhecimento é algo vivo e dinâmico, produzido historicamente de forma coletiva, com diferentes níveis de abstração e sistematização. Produzidos por homens concretos, em culturas determinadas e, por isso, carregados de valores e ideologias, os conhecimentos matemáticos se concretizam num jogo de forças da prática social, numa produção material e simbólica constituída na dinâmica interativa do mundo dos homens e das coisas.

Se partirmos dessa premissa poderemos reconhecer qual o conhecimento relevante a uma formação omnilateral?

É possível perscrutar sobre o objeto de estudo de determinada área do conhecimento expondo inicialmente os componentes que complexificam seu desvelamento no universo do currículo de formação e desenvolvimento humanos. Para tanto, elencamos alguns aportes a nosso ver necessários à sua formulação. São eles:

a) destacar o objeto de estudo da área a partir do caráter de sua especificidade, e isso nos remete dizer que sua centralidade investe em questões que essa área determina empírica e 
idealmente com reserva epistemológica;

b) destacar da literatura a centralidade (seu objeto) do conhecimento, sem apontar os seus objetivos, uma vez que se remetem necessariamente a conteúdos e comportamentos que o mediador/ estudioso espera agregar com a aprendizagem/socialização de seus estudos, por exemplo: "proporcionar o raciocínio lógico"; "oportunizar a crítica frente aos fenômenos de seu tempo", etc.

c) definir os conceitos e as categorias que serão trabalhados, ou seja, cada categoria utilizada deve ser claramente conceituada e situada ("em relação à") para não entendermos o fenômeno distante das práticas sociais.

Ressaltadas as premissas através das quais cercaremos o objeto de estudo das áreas do conhecimento por meio das categorias que historicamente o validam, podemos objetivar a apreensão de que os elementos verificados estão em relação uns com os outros. Compreendemos que se encontram dessa forma, uma vez que possuem determinadas arbitrariedades, porém que essas podem ser redefinidas porquanto se processam no espaço do movimento social. Uma nova racionalidade sobre esse fenômeno só se dará a partir do momento em que delegarmos o devido "tratamento das informações", de maneira que possamos apreender a excelência de dados sobre o objeto a ser reconhecido. A máxima a ser perquirida será de que o objeto de estudo de determinada área do conhecimento é o que tornou sua relevância no passado, como é no presente e o será no futuro, independentemente do número de apreensões e códigos requisitados pela modernidade, e não somente isso, mas muito além de uma instrumentalidade utilitária, o conhecimento que se elabora a partir dessa nova perspectiva formativa abre o debate dos estatutos científicos (seus axiomas e postulados) que necessitam ser revisitados com vistas a uma práxis transformadora.

\section{CONSIDERAÇÕES FINAIS}

A abordagem ao objeto da área do conhecimento com vistas a uma possível reformulação curricular, conforme dados que preliminarmente estamos recolhendo junto a algumas unidades escolares do município de Londrina e os estudos anteriores realizados em Florianópolis, procura objetivamente ressignificar o investimento pedagógico realizado no cotidiano escolar. Nossa preocupação sempre esteve voltada às práticas escolares que fossem de fato significativas a docentes e alunos. Os momentos de planejamento, conselhos de classe e reuniões pedagógicas são exemplos de tempo investido, acúmulo de tarefas, mas que, muitas vezes, redundam em gastos de energia sem que haja a totalidade do retorno esperado. A literatura hodierna tem apontado tal desgaste 9 .

Temos por premissa, então, que, ao delimitar o objeto da área de estudo, teceremos uma rede significativa de perspectivas ao docente ante uma formação humana que visa ao desenvolvimento humano pleno, por meio de uma educação omnilateral. Outro aporte aqui em destaque será a ressignificação curricular a partir dos eixos de referência do conhecimento na escola - o conhecimento epistêmico -, o que significa dizer que os elementos curriculares centrais ao trabalho escolar serão significativos do núcleo epistêmico, do saber elaborado, sistematizado, na instituição de ensino.

\section{REFERÊNCIAS}

ANTONIO, Clésio Acilino. Ordenamentos político-pedagógicos, parâmetros curriculares nacionais (PCNS) e educação física escolar uma leitura sobre as novas prescrições de um currículo ao ensino. 2000. 189 p. Dissertação (Mestrado em Educação) - CED, UFSC, Florianópolis, 2000.

$9 \quad$ Neste caso apontamos os Anais do Endipe (2002, 2004, 2006), por exemplo, nos quais estão sistematizadas inúmeras práticas que destacam o desgaste dos trabalhadores da educação diante das tarefas que continuamente realizam, mas que são obstaculizadas pela própria racionalidade ao sentido do objeto pretendido. 
BARRETO, Eli Maria de Melo. Processo de Construção Curricular: um caminho possível para a formação continuada do Professor. 130 p. 1993. Dissertação (Mestrado em Educação) - CED, UFSC, Florianópolis, 1993.

BRITTO, Néli Suzana Quadros. Grupo de formação de ciências no Movimento de Reorientação Curricular na RME de Florianópolis: espaço coletivo de reflexões acerca de uma prática inovadora. 2000. 117 p. Dissertação (Mestrado em Educação) - CED, UFSC, Florianópolis,. 2000.

CARDOSO, Ciro Flamarion. Epistemologia pós-moderna: a visão de um historiador. In: FRIGOTTO, Gaudêncio; CIAVATTA, Maria (Orgs.). Teoria e Educação no Labirinto do Capital. Petrópolis, RJ: Vozes, 2001.

DUARTE, Newton. A Individualidade Para-Si: contribuição a uma teoria histórico-social da formação do indivíduo. 2. ed. Campinas, SP: Autores Associados, 1999.

FRIGOTTO, Gaudêncio. A Produtividade da Escola Improdutiva: um (re)exame das relações entre Educação e Estrutura Econômico-Social Capitalista. São Paulo: Cortez: Autores Associados, 1984.

GARCIA, Walter Esteves. Educação: visão teórica e prática pedagógica. São Paulo: MacGraw-Hill do Brasil, 1977.

GIMENO SACRISTÁN, José. A construção do discurso sobre a Diversidade e suas práticas. In: ALCUDIA, Rosa et al. Atenção à Diversidade. Porto Alegre: Artmed, 2002 (Coleção Inovação Pedagógica, n. 3).

. O currículo: uma reflexão sobre a prática. Porto Alegre: ArtMed, 1998.

GRACIANI, Maria Stela Santos. Pedagogia Social de Rua: análise e sistematização de uma experiência vivida. São Paulo: Cortez: Instituto Paulo Freire, 1997.

IANNI, Otavio. A Sociedade Global. 8. ed. Rio de Janeiro: Civilização Brasileira, 1999.

KOSIK, Karel. Dialética do Concreto. 2. ed. Rio de Janeiro: Paz e Terra, 1995.

LUCKESI, Cipriano et al. Fazer universidade: uma proposta metodológica. 2. ed. São Paulo: Cortez, 1985.

MALINOWSKI, Bronisław. Uma Teoria Científica da Cultura. 3. ed. Rio de Janeiro: Zahar, 1975.

MARX, Karl; ENGELS, Friedrich. "Feuerbach: oposição das concepções materialista e idealista". In: BARATA-MOURA, José; CHITAS, Eduardo; MELO, Francisco; PINA, Álvaro. Marx \& Engels: obras escolhidas. Tradução de José Barata-Moura, Educardo Chitas, Francisco Silvestre e Álvaro Pina. Tomo I. Lisboa, Portugal: Avante!; Moscou, URSS: Progresso, 1982.

MOREIRA, Antonio Flavio Barbosa (Org.). Currículo: Políticas e Práticas. Campinas: Papirus, 1999. . Currículos e Programas no Brasil. 10. ed. São Paulo: Papirus, 2003.

; SILVA, Tomaz Tadeu da. Currículo, Cultura e Sociedade. São Paulo: Cortez, 1994.

PLATT, Adreana Dulcina. Formação humana: currículo para o desenvolvimento humano. Revista Espaço do currículo, v. 2, n. 1, p. 141-157, mar./set. 2009.

. A Ressignificação do Processo de Avaliação em Perspectiva ao Pleno Desenvolvimento Humano (Comunicação). In: I Simpósio Internacional “Educação e Filosofia". Marília, SP: UNESP, 2006 (CD-ROM).

PREFEITURA MUNICIPAL DE FLORIANÓPOLIS. Secretaria Municipal de Educação. Coordenadoria de Ensino. Traduzindo em Ações: das diretrizes a uma proposta curricular. Florianópolis, SC, 1996.

SANTOMÉ, Jurjo Torres. Globalização e Interdisciplinaridade. Porto Alegre, RS: Artmed, 1998. 
SANTOS, Lucíola Licínio de Castro Paixão. Relação entre os processos pedagógicos, os sujeitos e a tecnologia. In: ROSA, Dalva Eterna Gonçalves; SOUZA, Vanilton Camilo de (Orgs.). Políticas organizativas e curriculares, educação inclusiva e formação de professores. Rio de Janeiro: DP\&A, 2002. p. 139-150.

SAVIANI, Dermeval. Pedagogia Histórico-Crítica: primeiras aproximações. 11. ed. Campinas, SP: Autores Associados, 2011.

SCHAFF, Adam. História e Verdade. São Paulo: Martins Fontes, 1978.

SEMERARO, Giovanni. Anotações para uma teoria do conhecimento em Gramsci. Revista Brasileira de Educação, n. 16, jan.-abr., 2001.

REIS, Nelio Roberto dos. Teses de Ecologia Geral (Palestra). Londrina, PR: Universidade Estadual de Londrina, 2003.

TYLER, Ralph W. Princípios básicos de currículo e ensino. Porto Alegre: Globo, 1974.

WIGGERS, Verena. A Educação Infantil no Movimento de Reorientação Curricular do Município de Florianópolis. 1999. 221 p. Dissertação (Mestrado em Educação) - CED, UFSC, Florianópolis, 1999. 
Recebido em: 25/05/2018

Aceito em: $23 / 08 / 2018$

Publicado em: 03/10/2019 